\title{
Termal kamera ve NDVI sensörü kullanılarak domatesin fizyolojik özelliklerinin tahminlenmesi
}

\section{Estimation of physiological traits of tomato using thermography technique and NDVI sensor}

\author{
Gökhan ÇAMOĞLU ${ }^{*}$ iD, Kürşad DEMIREL ${ }^{2}$ iD, Levent GENÇ ${ }^{3}$ iD \\ ${ }^{1}$ Çanakkale Onsekiz Mart Üniversitesi, Ziraat Fakültesi, Tarımsal Yapılar ve Sulama Bölümü, Çanakkale \\ ${ }^{2}$ Çanakkale Onsekiz Mart Üniversitesi, Mimarlık ve Tasarım Fakültesi, Peyzaj Mimarlığı Bölümü, Çanakkale \\ ${ }^{3}$ Çanakkale Onsekiz Mart Üniversitesi, Mimarlık ve Tasarım Fakültesi, Şehir ve Bölge Planlama Bölümü, Çanakkale
}

To cite this article:

Çamoğlu, G., Demirel, K. \& Genç, L. (2019). Termal kamera ve NDVI sensörü kullanılarak domatesin fizyolojik özelliklerinin tahminlenmesi. Harran Tarım ve Gıda Bilimleri Dergisi, 23(1): 78-89. DOI: $10.29050 /$ harranziraat.44 9224

\section{Address for}

Correspondence:

Gökhan ÇAMOĞLU

e-mail:

camoglu@comu.edu.tr

\section{Received Date}

30.07.2018

Accepted Date:

18.01.2019

(c) Copyright 2018 by Harran University Faculty of Agriculture. Available on-line at www.dergipark.gov.tr/harranzira at

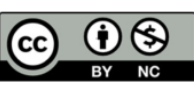

This work is licensed under a Creative
Commons AttributionCommons Attribution-
Non Commercial 4.0 Intermational License.

\section{ÖZ}

Bu çalışmada; domates (Lycopersicum esculentum L. cv Full F1) bitkisinde, bitki su stresi indeksi (CWSI) ve Normalize Edilmiş Vejetatif Değişim İndeksi (NDVI) sensöründen elde edilen veriler kullanılarak su stresi düzeyinin, ayrıca CWSI ve NDVI değerleri ile bitkinin bazı fizyolojik özellikleri (stoma iletkenliği, yaprak su potansiyeli, yaprak oransal su içeriği ve klorofil) arasındaki ilişkilerin belirlenmesi amaçlanmıştır. Çanakkale ilinde 2017 yılında yürütülen çalışmada dört farklı sulama konusu (\%100, \%75, \%50 ve \%25) ele alınmıştır. Çalışma sonucunda, uzaktan algılama indekslerinin her ikisi de su stresi karşısında belirgin tepkiler vermiş̧tir. Bu durumda her iki indeks de kullanılarak domatesin su stresinin başarılı bir şekilde belirlenebileceği söylenebilir. Buna ilaveten ölçümü zor, zaman alıcı ve bitkiye zarar verebilen fizyolojik ölçümlerin CWSI ve NDVI değerlerinin her ikisini de kullanarak yüksek doğrulukla tahmin edilebileceği sonucuna varılmıştır.

Anahtar Kelimeler: Domates, Su stresi, Sulama, CWSI, Spektral indeks

\section{ABSTRACT}

The aim of this study are to determine the water stress level using the values obtained from the Normalized Difference Vegetation Index (NDVI) sensor and the Crop Water Stress Index (CWSI) and also relationships among some physiological traits (stomatal conductance, relative leaf water content, leaf water potential, chlorophyll) of plant and CWSI/NDVI. The study was conducted in Çanakkale province in 2017 investigated four different irrigation treatments $(100 \%, 75 \%, 50 \%$ and $25 \%)$. As a result of the study, both remote sensing indices gave important responses to water stress. In this case, it can be said that the water stress of the tomato can be determined successfully by using both indices. The results indicated that physiological measurements that are difficult to measure, time consuming and damaging to the plant can be estimated with high accuracy by combined use of CWSI and NDVI indices.

Key Words: Tomato, Water stress, Irrigation, CWSI, Spectral index

\section{Giriş}

Bitkilerin içinde bulundukları stres mekanizmasını anlamaya yönelik olarak fotosentez, klorofil, stoma iletkenliği yaprak su durumu gibi birçok fizyolojik ölçüm yapılabilmektedir. Ancak söz konusu ölçümler için

\section{çok sayıda pahalı cihaza gereksinim} duyulmaktadır. Bunların maliyetli olmalarının yanı sıra fazla iş gücü gerektirmesi, uzman personele intiyaç duyulması, bitkilere zarar verebilmesi, araziyi temsil gücünün düşük olması gibi bazı dezavantajları da bulunmaktadır. Bu nedenle günümüzde böyle olumsuz etkileri ortadan 
kaldırabilecek bitki stresini tanımlamaya yönelik çalışmalara ağırlık verilmektedir. Bu anlamda stresi belirlemeye yönelik olarak teknolojinin de gelişmesiyle artık bitki sıcaklıklarını ve yansıma indekslerini veren cihazlar kolaylıkla kullanılabilir duruma gelmiştir.

Başta su stresi olmak üzere hastalık, yabancı ot gibi çevresel stres faktörleri bitkide fizyolojik değişikliklere sebep olmaktadır. Stres altındaki bitkilerin yapraktaki su içerikleri ve pigment yapıları değişime uğradığı için strese maruz kalan bitkiler sağlıklı bitkilerden farklı spektral yansımalara sahip olmaktadır. Fizyolojik değişikliğe örnek olarak klorosis (yaprak sararması) sebebiyle bitki yapraklarındaki renklerin değişmesi verilebilir. Yapraklardaki sarı renk, klorofilin parçalanmasıyla meydana gelir. Bu durumda yansıyan yeşil ışık azalır ve yansıyan kırmızı ışık artar (Covey, 1999). Görünür bölgedeki bu değişimin yanı sıra yakın kızılötesi bölgede de sağlıklı bitkiler stresli bitkilerden daha yüksek yansıma göstermektedir (Jacquemoud ve Ustin, 2001). Bu iki bölgeden yararlanılarak hesaplanan Normalize Edilmiş Vejetatif Değişim İndeksi (NDVI) de bitki sağlığını izlemede önemli rol oynamaktadır. Nitekim NDVI değerinin yapraktaki pigment değişimine ve yaprak su potansiyeline duyarlı olduğu yapılan bilimsel çalışmalarda da bildirilmiştir (Datt, 1998; Köksal ve ark., 2010; Camoglu ve ark., 2013).

Termal kameralar yardımıyla belirlenen bitki taç sıcaklıklarından yararlanarak bitki su stresi indeksinin (CWSI) belirlenmesinde, Jones (1999) yaptığı çalışmada farklı alt ve üst baz referansları kullanmışlardır. Hesaplamada, üst baz için petrolyum jel (vazelin) ile tamamen kaplanmış bitkiler, alt baz için de yüzeyleri tamamen ıslatılmış bitkiler kullanılmıştır. Ülkemizde bu teknikleri kullanarak bitki su stresini belirlemeye yönelik çalışmaların henüz yeterli olmadığı görülmektedir. Konuyla ilgili olarak NDVI değerini doğrudan veren sensörlerin kullanımına yönelik herhangi bir çalışmaya rastlanmazken, termografi tekniğini kullanarak su stresinin belirlenmesi üzerine birkaç çalışmaya rastlanmaktadır. Ancak söz konusu çalışmalar da farklı bitkilerde yapılmıştır. Çamoğlu ve Genç (2013) tarafından yapılan çalışmada, su stresine bağlı olarak taze fasulyenin su kullanımının, veriminin ve bazı morfo-fizyolojik özelliklerinin değişimi ve bu değişimin kızılötesi termal görüntüleme tekniği ile hiperspektral yansıma verilerini kullanarak belirlenebilme olanakları araştırılmıştır. Demirel ve ark. (2014), farklı sulama ve azot seviyelerinde saksı ortamında yetiştirilen rokanın sıcaklık değişimlerini termal kameralar yardımıyla belirlemişlerdir. Akçan ve ark. (2016), çim bitkisinin su stresinin termografi tekniğini kullanarak belirlenebilme olanaklarını araştırmışlardır. Sonuç olarak, termal görüntüler kullanılarak bitkilerde su stresi konusu üzerine araştırmalara yer verilirken ülkemizde böyle çalışmaların henüz yaygınlaşmadığı görülmektedir. Bunun yanında domates bitkisinde de dünyada bu konuları ele alan çalışmaların yetersiz olduğu anlaşılmaktadır. Bu çalışmayla, ülkemizde bu konuda yapılacak araştırmalara literatür yönünden katkı sağlanması hedeflenmiştir. Diğer yandan, çalışma ülkemizde hassas teknolojilerin kullanımının çiftçi koşullarında yaygınlaşması yönünde önemlidir.

Çalışmada, bitkiye dayalı izleme tekniklerinden biri olan termal görüntüleme ile elde edilen CWSI ile NDVI sensöründen elde edilen değerler kullanılarak domatesin su stresi düzeyinin ve ayrıca söz konusu indeksler ile bazı fizyolojik özellikler (stoma iletkenliği, yaprak su potansiyeli, yaprak oransal su içeriği ve klorofil) arasındaki ilişkilerin belirlenmesi amaçlanmıştır. Bu amaçla, CWSI ve NDVI ile domatesin fizyolojik özellikleri arasında tek ve çok değişkenli regresyon modelleri oluşturulmuştur. Böylece, ölçümü zor ve zaman alıcı bu özelliklerin bitkiye zarar vermeden, hızlı ve doğru bir şekilde belirlenebilme potansiyeli ortaya konulmuştur.

\section{Materyal ve Yöntem}

\section{Araştırma alanının tanımı}

Çalışma; 2017 yılında, Çanakkale'de, sofralık domates (Lycopersicum esculentum L. cv Full F1) bitkisinde, tarla koşullarında yürütülmüştür. 
Denemeye başlamadan önce alanı temsil eden üç farklı noktadan, toprak profilinin $0-30 \mathrm{~cm}, 30-60$ $\mathrm{cm}$ ve $60-90 \mathrm{~cm}$ derinliklerinden bozulmuş ve bozulmamış toprak örnekleri alınmış olup bunlardan tarla kapasitesi, solma noktası, hacim ağırlığı ve toprak bünyesi belirlenmiştir (Çizelge 1). Deneme alanında kullanılan suyun $\mathrm{EC}$ ve $\mathrm{pH}$ değerleri sırasıyla $1.3 \mathrm{dS} \mathrm{m}^{-1}$ ve 7.9 olarak ölçülmüştür.

Çizelge 1. Deneme alanı topraklarının bazı fiziksel analiz sonuçları

Table 1. Some physical analysis results of the soil in the study area

\begin{tabular}{|c|c|c|c|c|c|c|c|c|}
\hline \multirow{2}{*}{$\begin{array}{c}\text { Toprak } \\
\text { derinliği } \\
\text { Soil depth } \\
\text { (cm) }\end{array}$} & \multirow[t]{2}{*}{$\begin{array}{l}\text { Bünye } \\
\text { Texture }\end{array}$} & \multirow{2}{*}{$\begin{array}{l}\text { Hacim ağırlığı } \\
\text { Bulk density } \\
\quad\left(\mathrm{g} \mathrm{cm}^{-3}\right)\end{array}$} & \multicolumn{2}{|c|}{$\begin{array}{l}\text { Tarla kapasitesi } \\
\text { Field capacity }\end{array}$} & \multicolumn{2}{|c|}{$\begin{array}{l}\text { Solma noktası } \\
\text { Wilting point }\end{array}$} & \multicolumn{2}{|c|}{$\begin{array}{c}\text { Kullanılabilir } \\
\text { su tutma kapasitesi } \\
\text { Available water holding } \\
\text { capacity }\end{array}$} \\
\hline & & & $\begin{array}{l}\mathrm{Pv} \\
(\%)\end{array}$ & $\begin{array}{c}\mathrm{d} \\
(\mathrm{mm})\end{array}$ & $\begin{array}{l}\mathrm{Pv} \\
(\%)\end{array}$ & $\begin{array}{c}\mathrm{d} \\
(\mathrm{mm})\end{array}$ & $\begin{array}{l}\mathrm{Pv} \\
(\%)\end{array}$ & $\begin{array}{c}\mathrm{d} \\
(\mathrm{mm})\end{array}$ \\
\hline $0-30$ & SL & 1.49 & 34.9 & 104.7 & 23.9 & 71.7 & 11.0 & 33.0 \\
\hline $30-60$ & SL & 1.53 & 33.9 & 101.7 & 21.6 & 64.8 & 12.3 & 36.9 \\
\hline $60-90$ & SL & 1.58 & 34.9 & 104.7 & 21.3 & 63.9 & 13.7 & 40.8 \\
\hline \multicolumn{4}{|c|}{ Toplam $(0-90 \mathrm{~cm})$} & 311.1 & & 200.4 & & 110.7 \\
\hline
\end{tabular}

Denemenin yürütüldüğü aylara (Mayıs-Ekim) ilişkin olarak uzun yıllık ortalama sıcaklık değeri $21.1^{\circ} \mathrm{C}$, bağıl nem \% 68.4 ve rüzgar hızı $3.7 \mathrm{~m} \mathrm{sn}^{-}$ ${ }^{1}$ dir. 2017 yılı için ise söz konusu değerler sırasıyla; $22.3{ }^{\circ} \mathrm{C}, \% 60.1$, ve $3.3 \mathrm{~m} \mathrm{sn}^{-1}$ olmuştur (Anonim, 2018).

\section{Deneme deseni}

Araştırma, tesadüf blokları deneme desenine göre 4 sulama konusu 3 tekerrürlü olarak yürütülmüştür (Çizelge 2). Deneme, 24 Mayıs 2017 tarihinde domates fidelerinin dikimi ile başlamış olup 26.10.2017 tarihinde son hasat yapılarak bitmiştir. Domatesin dikim normu 100x66 cm olarak alınmıştır. Her parselde 4 bitki sırası oluşturulmuş ve her bitki sırasına 10 adet bitki dikilmiştir. Parsel aralarına toprağın adveksiyon etkisini ortadan kaldırmak amacıyla bir sıra daha domates dikilmiştir. Çalışmada ölçümlerin tümü ortadaki iki bitki sırasında yapılmıştır.

Araştırmada bitkilerin sulanması için damla sulama sistemi kullanılmış olup istatistiksel dizayna uygun olarak tesis edilmiştir.

Çizelge 2. Denemede ele alınan sulama konuları

Table 2. Irrigation treatments investigated in the experiment

\begin{tabular}{cl}
\hline $\begin{array}{l}\text { Sulama konusu } \\
\text { Treatment }\end{array}$ & $\begin{array}{l}\text { Açıklama } \\
\text { Explanation }\end{array}$ \\
\hline I-100 & $0-90 \mathrm{~cm}$ toprak derinliğindeki kullanılabilir nemin $\% 40 \pm 5^{\prime} \mathrm{i}$ tüketildiğinde eksilen nemin tarla \\
& kapasitesine tamamlanması (kontrol) \\
$\mathrm{I}-75$ & $\mathrm{l}-100$ konusunda tüketilen suyun $\% 75^{\prime} \mathrm{i}$ \\
$\mathrm{I}-50$ & $\mathrm{l}-100$ konusunda tüketilen suyun $\% 50^{\prime} \mathrm{si}$ \\
$\mathrm{I}-25$ & $\mathrm{l}-100$ konusunda tüketilen suyun $\% 25^{\prime} \mathrm{i}$ \\
\hline
\end{tabular}

\section{Kültürel işlemler}

Dikimden önce pullukla sürüm yapılmış ve ardından rotatiller ile sürülerek dikime hazır duruma getirilmiştir. Toprak analiz sonuçlarına göre, dikimle birlikte damla sulama sisteminde yer alan venturi gübreleme sistemiyle ilk gübreleme (Dekara 5 kg AquaDrip 20-20-20-TE) yapılmıştır. Diğer gübreleme işlemleri çiçeklenme ve hasat dönemleri arasında (5 kg da-1 olmak üzere üç kez daha) yapılmıştır. Tüm yetişme periyodu boyunda ortaya çıkan yabancı otlarla mücadele elle, frezeyle ve herbisit uygulanarak yapılmıştır. Ortaya çıkan/çıkabilecek diğer hastalık ve zararlılarla mücadelede ise kükürt ve insektisit kullanılmıştır.

\section{Uygulanan sulama suyu miktarı}

Denemede konulara uygulanan sulama suyu miktarının belirlenmesinde toprak nem sensörleri (DECAGON 10HS) kullanılmıştır. Sensörlerden 
gelen verilerin kaydedilmesinde veri kaydediciler (DECAGON EM50) kullanılmıştır. Çalışmada toplam 9 adet sensör kullanılmış ve bunlar $1-100$ konusunun her bir tekerrüründe toprağın $0-30 \mathrm{~cm}$ $30-60 \mathrm{~cm}$ ve $60-90 \mathrm{~cm}$ katmanlarına yerleştirilmiştir. Deneme başlamadan önce söz konusu sensörler mevcut toprak koşullarına göre kalibre edilmiş ve elde edilen eşitliliklere göre gerçek nem değerleri tahmin edilmiştir. Her sulamadan önce bu değerlerden yararlanılarak konulara uygulanacak sulama suyu miktarları Eşitlik 1 yardımıyla hesaplanmıştır.

$$
I=(T K-M N) \times P \times A
$$

Eşitlikte; I: Sulama suyu miktarı (litre), TK: $90 \mathrm{~cm}$ toprak derinliğindeki tarla kapasitesi değeri $(\mathrm{mm})$, MN: Sulamadan hemen önceki mevcut nem değeri (mm) P: Örtü yüzdesi (en az \%30 alınmıştır), A: Parsel alanı $\left(\mathrm{m}^{2}\right)$

\section{Yapılan ölçümler ve hesaplamalar}

Çalışma kapsamında yapılan ölçümler ve bu ölçümlerde kullanılan cihazlar Çizelge 3 'de sunulmuştur. Tüm ölçümler, dikimden sonraki 43. günde $\left(\mathrm{DSG}_{43}\right)$ başlamış ve $\mathrm{DSG}_{113}$ 'de bitmiştir. Ölçümlerin tümü her iki sulamada bir ve sulama öncesinde yapılmıştır (Şekil 1).

Çizelge 3. Çalışmada yapılan ölçümler ve analizler Table 3. Measurements and analyzes in study

\begin{tabular}{|c|c|c|}
\hline $\begin{array}{l}\text { Ölçüm grubu } \\
\text { Measurement group }\end{array}$ & $\begin{array}{l}\text { Ölçümler ve hesaplamalar } \\
\text { Measurements and calculations }\end{array}$ & $\begin{array}{l}\text { Kullanılan cihaz veya yöntem } \\
\text { Device or method used }\end{array}$ \\
\hline $\begin{array}{l}\text { Fizyolojik ölçümler } \\
\text { Physiological } \\
\text { measurements }\end{array}$ & $\begin{array}{l}\text { Stoma iletkenliği } \\
\text { Klorofil okuması } \\
\text { Yaprak su potansiyeli } \\
\text { Yaprak oransal su içeriği }\end{array}$ & $\begin{array}{l}\text { Porometre (Decagon SC-1) } \\
\text { Klorofilmetre (Fieldscout CM1000) } \\
\text { Basınç odası (PMS Model 1000) } \\
\text { Gravimetrik yöntem }\end{array}$ \\
\hline $\begin{array}{l}\text { Uzaktan algılama ölçümleri } \\
\text { Remote sensing } \\
\text { measurements }\end{array}$ & $\begin{array}{l}\text { Normalize Edilmiş Vejetatif Değişim } \\
\text { İndeksi (NDVI) } \\
\text { Termal indeks (CWSI) }\end{array}$ & $\begin{array}{l}\text { NDVI sensörü (Decagon SRS-Nr) } \\
\text { Termal kamera (Fluke Ti27) }\end{array}$ \\
\hline
\end{tabular}

\section{Fizyolojik ölçümler}

Fizyolojik ölçümlerin tümü 11.00-14.00 saatleri arasında yapılmıştır. Stoma iletkenliği, her tekerrürde rastgele seçilen 3 bitkinin güneş gören ve olgunluğunu tamamlamış birer yaprağında yapılmıştır (Şekil 1a). Yapraktaki klorofil içeriğinin göstergesi olarak kullanılan klorofil okumaları, her bir bitkinin üç farklı yaprağından aynı yaprakta üçer kez ölçüm almak suretiyle yapılmıştır (Şekil 1b). Ölçümlerde ışıklılık indeksi 4-5 arasında tutulmuştur. Yaprak su potansiyeli, her bir tekerrürde 3 farklı bitkiden alınan sürgünlerde ölçülmüştür (Şekil 1c). Ölçümde bitkinin söz konusu dönemdeki tam gelişmiş güneş gören kısımları kullanılmıştır. Yaprak oransal su içeriği, her tekerrürden üç farklı bitkiden gelişimini tamamlamış üç yaprak örneği alınarak Eşitlik 2 yardımıyla belirlenmiştir (Ackley, 1954; Smart ve Bingham, 1974).

$$
Y O S \dot{I}=\frac{Y A-K A}{T A-K A} x 100
$$

Eşitlikte; YOSi: Yaprak oransal su içeriği (\%), YA: Yaş ağırlık (mg), KA: $70{ }^{\circ} \mathrm{C}$ sıcaklıkta 24 saat bekletme sonrasındaki kuru ağırlık (mg), TA: 24 saat saf su içerisinde bekletilerek elde edilen turgor ağırlık (mg).
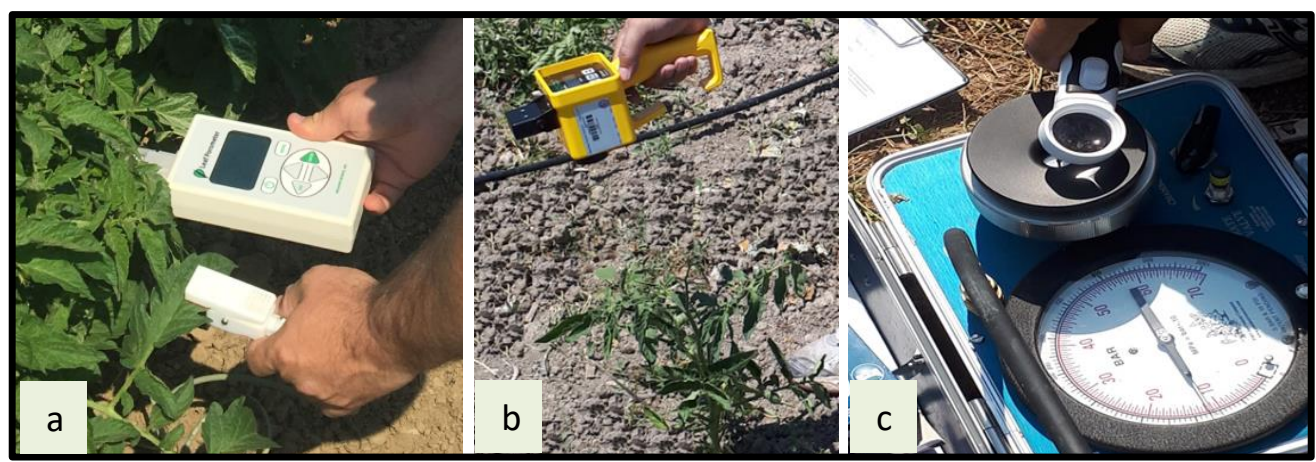

Şekil 1. Stoma iletkenliği (a), klorofil okuması (b) ve yaprak su potansiyeli (c) ölçümleri

Figure 1. Measurements of stomatal conductance (a), chlorophyll reading (b) and leaf water potential (c) 


\section{Uzaktan algılama ölçümleri}

Termal ve NDVI ölçümleri, havanın bulutsuz ve rüzgar hızının $2 \mathrm{~m} \mathrm{~s}^{-1}$ den daha az olduğu günlerde, sulama öncesinde ve gün içinde stresin en fazla görüldüğü saat 11:00 ile 14:00 arasında yapılmıştır (Şekil 2).

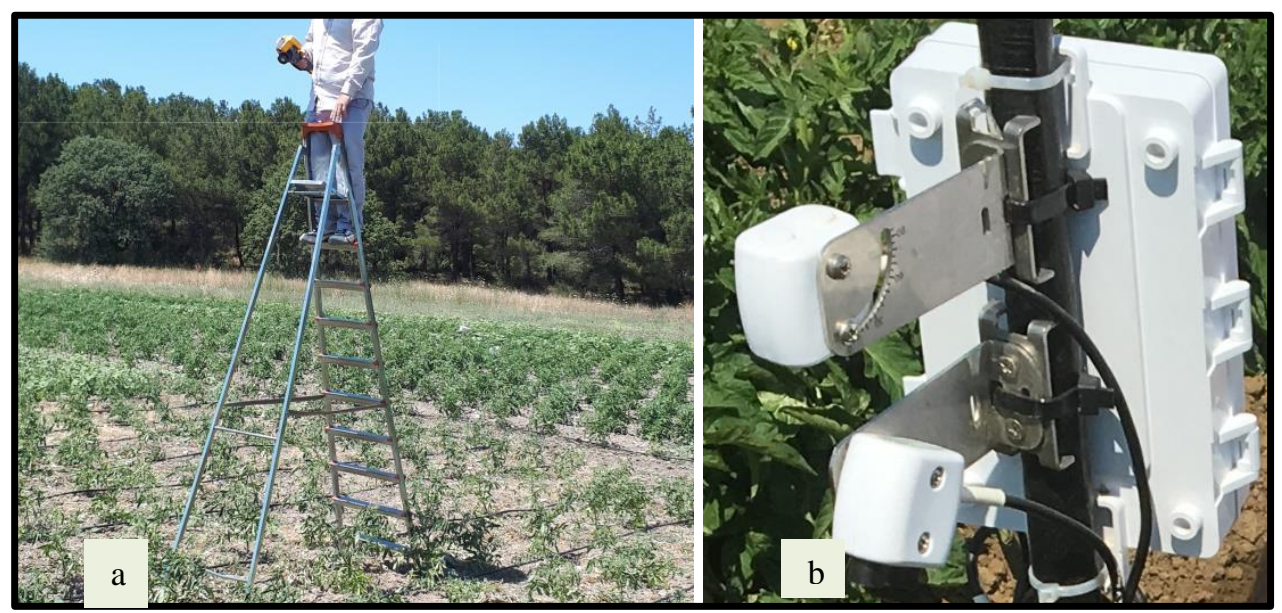

Şekil 2. Termal (a) ve NDVI (b) ölçümleri

Figure 2. Thermal (a) and NDVI (b) measurements

Termal görüntülerde geniş açılı lens $\left(46^{\circ} \times 34^{\circ}\right)$ kullanılmış ve emissivite değeri $0.98^{\prime} \mathrm{e}$ ayarlanmıştır. Ölçümler, geniş açılı lensle yaklaşık $3.5 \mathrm{~m}$ yükseklikten $5.9 \mathrm{~m}^{2}$ lik bir alanı görecek şekilde gerçekleştirilmiştir (Şekil 2a). Arka plan sıcaklığının belirlenmesinde alüminyum folyodan yararlanılmıştır (Jones ve ark., 2002). Bitki su stresi indeksi (CWSI) Eşitlik 3 yardımıyla belirlenmiştir. CWSI değerlerinin belirlenmesi için gerekli alt ve üst baz değerleri ampirik eşitlikler yardımıyla hesaplanmıştır.

$$
C W S I=\frac{\left(\mathrm{T}_{\mathrm{c}}-T_{\text {tslak }}\right)}{\left(\mathrm{T}_{\mathrm{kuru}}-T_{\text {lslak }}\right)}
$$

Eşitliklerde; $\mathrm{T}_{c}$ : Taç sıcaklığı $\left({ }^{\circ} \mathrm{C}\right), \mathrm{T}_{\text {sslak: }}$ Islak referans yüzeyin sıcaklığı $\left({ }^{\circ} \mathrm{C}\right), \mathrm{T}_{\text {kuru }}$ : Kuru referans yüzeyin sıcaklığı ( $\left.{ }^{\circ} \mathrm{C}\right)$

Ampirik yöntemde $\mathrm{T}_{\text {ıslak }}$ Eşitlik 4 yardımıyla (Monteith ve Unsworth, 1990; O'Shaughnessy ve ark. 2011), $T_{\text {kuru }}$ ise ölçülen hava sıcaklığına $5{ }^{\circ} \mathrm{C}$ ilave edilerek tahmin edilmiştir (Cohen ve ark., 2005, Möller ve ark., 2007). Bu yöntemle hesaplanan termal indeks, $\mathrm{CWSI}_{\mathrm{e}}$ olarak gösterilmiştir.

$$
T_{w e t} \approx T_{a}-\frac{e_{s}\left(T_{a}\right)-e_{a}}{\Delta+\gamma}
$$

Eşitlikte; $\mathrm{T}_{\mathrm{a}}$ : hava sıcaklığı $\left({ }^{\circ} \mathrm{C}\right)$, $\mathrm{e}_{\mathrm{s}}$ : havanın doygun buhar basıncı $(\mathrm{kPa}), \mathrm{e}_{\mathrm{a}}$ : havanın gerçek buhar basıncı $(\mathrm{kPa}), \Delta$ : buhar basıncı eğrisinin eğimi $\left(\mathrm{kPa}{ }^{\circ} \mathrm{C}^{-1}\right)$, $\mathrm{v}$ : psikrometrik sabite $\left(\mathrm{kPa}^{\circ} \mathrm{C}^{-1}\right)$ Görüntü işleme ve analizler Çamoğlu ve Genç (2013) tarafından belirtilen şekilde yapılmıştır.

Normalize Edilmiş Vejetatif Değişim Indeksi (NDVI) ölçümleri SRS-NDVI sensörleri kullanılarak yapılmıştır (Şekil 2b). Cihaz NIR ve RED dalga boyundaki yansımaları ölçüp Eşitlik 5 (Rouse ve ark., 1973) yardımıyla hesaplayarak doğrudan NDVI değerini vermektedir. NDVI değerleri, her bir tekerrürde parseli temsil eden üç bitki üzerinde bitki taç genişliğini aşmayacak şekilde gerçekleştirilmiştir. NDVI sensöründen alınan değerler datalogger (Decagon M50) kullanılarak kaydedilmiştir.

$$
\mathrm{NDVI}=\frac{\mathrm{R}_{800}-\mathrm{R}_{630}}{\mathrm{R}_{800}+\mathrm{R}_{630}}
$$

\section{istatistiksel analiz}

Denemede gerçekleştirilen uygulamaların sonucunda elde edilen veriler arasındaki farkın önemli olup olmadığı $(p=0.05)$ tek yönlü varyans analizi (One-Way ANOVA) ile belirlenmiştir. Farkın önemli olması durumunda, konular arasındaki farklılı̆ı belirlemek için Duncan testi kullanılmıştır. Ele alınan özellikler arasındaki modelleri belirlemek amacıyla tek değişkenli regresyon (TDR) ve enter yöntemi kullanılarak çok 
değişkenli doğrusal regresyon (ÇDDR) analizi yapılmıştır. Tüm istatistiki değerlendirmelerde SPSS 20.0 paket programı kullanılmıştır.

\section{Araştırma Bulguları ve Tartışma}

\section{Uzaktan algılama indeksleri}

Yetişme periyodu boyunca domatese ilişkin ölçülen Normalize Edilmiş Vejetatif Değişim Indeksi (NDVI) ve ampirik olarak hesaplanan Bitki Su Stresi İndeksi $\left(\mathrm{CWSI}_{\mathrm{e}}\right.$ ) değerlerinin konulara göre değişimleri Şekil 3'de verilmiştir. Dönem boyunca ölçülen NDVI ve $\mathrm{CWSI}_{\mathrm{e}}$ değerleri konulara göre sırasıyla 0.46 ile 0.80 ve 0.40 ile0.97 arasında değişmiştir. Genel itibariyle ilk ölçümden sonraki tüm ölçümlerde I-100 konusuna ilişkin NDVI değeri en yüksek değerleri alırken, $\mathrm{CWSI}_{\mathrm{e}}$ en düşük değerleri almıştır. Stresin artışına bağlı olarak NDVI değerleri azalmış, $\mathrm{CWSI}_{\mathrm{e}}$ değerleri ise artmıştır. Illk iki ölçümde (DSG 43 ve $\left.D S_{50}\right)$ konuların NDVI değerleri arasında istatistiksel bir fark oluşmazken sonraki ölçümlerde aralarındaki farklar belirgin hale gelmiştir. Bu durum, bitkinin erken dönemde henüz yapraktaki pigmentlerin tam olarak zarara uğramadığını göstermektedir. Sönmez ve ark. (2015) domateste tuz stresi koşullarında spektral yansıma tepkilerini araştırdıkları çalışmalarında, stresin bir süre devam ettikten sonra NDVI değerinin konuları ayırt edici etkisinin olduğunu bildirmişlerdir.

Mastrorilli ve ark. (2010) domateste su stresinin değerlendirilmesinde NDVI değerinin 0.6 ile 0.9 arasında değiştiğini ve anlık sulama programlamasında kullanışlı olamayacağını belirtmişlerdir. Çamoğlu ve ark. (2018) benzer şekilde NDVI değerinin biber bitkisinde tam sulanan bitkiler ile hafif stres uygulanan bitkileri ayırt edemediğini bildirmişlerdir. Ancak bu çalışmada, çoğu ölçümde NDVı değeri konuları ayırt etmede başarılı sonuçlar vermiştir. Nicacias (2009) domateste stresli ve stressiz bitkilerde yaptığı NDVI ölçümlerinde, söz konusu değerin domates çeşitlerine ve ölçüm zamanına göre 0.21 ile 0.84 arasında değiştiğini ve stresin artışına bağı olarak NDVI değerinin azaldığını bildirmiştir. $\mathrm{CWSI}_{\mathrm{e}}$ değerlerinde ilk ölçümden sonra konular arasında istatistiksel bir farklılık oluşmuştur. Özellikle $\mathrm{DSG}_{73}$ 'den sonra tüm konuların farklı grupta yer alması, söz konusu indeksin sulama konularını ne derece başarılı ayırabildiğinin bir göstergesidir. Morales ve Urrestarazu (2013), domateste transpirasyonu etkileyen su stresi gibi diğer bir stres faktörü olan tuzun etkisinin de termografi tekniğini kullanarak başarılı bir şekilde tespit edilebileceğini belirtmişlerdir. Nardella ve ark. (2008) domateste üç farklı sulama düzeyi (\%100, \%75 ve \%50) uyguladıkları çalışmalarında, ampirik olarak hesaplanan CWSI değerlerinin zamana ve konulara bağlı olarak 0.18 (\%100) ile 0.74 (\%50) arasında değişiklik gösterdiğini ve istatistiksel olarak konuların birbirinden ayrıldığını belirtmişlerdir.
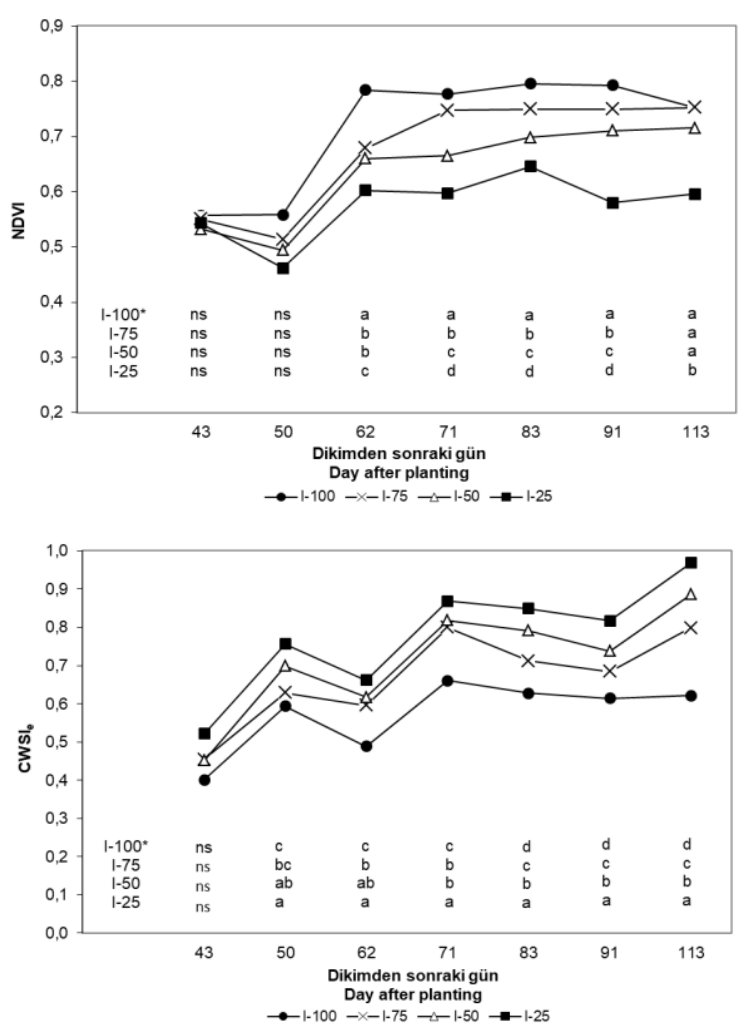

Şekil 3. Konulara göre NDVI ve CWSI değerlerinin değişimi Figure 3. The change of NDVI and CWSI values according to treatments

Fizyolojik özellikler ile uzaktan algılama indeksleri arasındaki ilişkiler

\section{Stoma iletkenliği ile indeksler arasındaki ilişkiler}

Yetiştirme periyodu boyunca her ölçüm için stoma iletkenliği ile NDVI ve $\mathrm{CWSI}_{\mathrm{e}}$ değerleri arasındaki tek değişkenli regresyon (TDR) analizleri Şekil 4'de, çok değişkenli doğrusal 
regresyon (ÇDDR) analizleri ise Çizelge 4'de gösterilmiştir. İlk ölçümde ( $\mathrm{DSG}_{43}$ ) konulara henüz geçilmediği için, bu tarihe ilişkin regresyon analizi yapılmamıştır. Şekil 4 incelendiğinde, stoma iletkenliği ile NDVI arasında aynı yönde, $\mathrm{CWSI}_{\mathrm{e}}$ ile arasında ise ters yönde bir ilişkinin olduğu görülmektedir. $\mathrm{R}^{2}$ değerleri, ölçüm günlerine bağlı olarak NDVI için $0.46\left(D_{5 G}\right)$ ile $0.94\left(D G_{71}\right)$ ve $\mathrm{CWSI}_{\mathrm{e}}$ için $0.55\left(\mathrm{DSG}_{50}\right)$ ile $0.96\left(\mathrm{DSG}_{113}\right)$ arasında değişmiştir. Her iki indekste de ilk ölçümde $R^{2}$ $p<0.05$ düzeyinde önemli olurken, diğer günlerde $p<0.001$ düzeyinde önemli bulunmuştur.

Çizelge 4 incelendiğinde, her iki indeksin de eşitlikte yer alması ile tüm ölçüm günlerinde $R^{2}$ değerlerinin arttığı görülmektedir. Söz konusu değerler 0.70 ile 0.98 arasında değişmiştir. En düşük ve en yüksek değerler sırasıyla ilk $\left(D S G_{50}\right)$ ve son $\left(D G_{113}\right)$ ölçümde gerçekleşmiştir. İlk ölçümdeki ( $\left(D S G_{50}\right) R^{2}$ değerinin önemlilik seviyesi TDR analizinde \%5 iken, ÇDDR analizinde \%1 düzeyine yükselmiştir.

Çizelge 4. Stoma iletkenliği ile indeksler arasındaki ÇDDR analizi sonuçları

Table 4. The results of ÇDDR analysis between stomatal conductance and indices

\begin{tabular}{|c|c|c|c|c|c|}
\hline DSG & $\begin{array}{l}\text { Model } \\
\text { Model }\end{array}$ & $\begin{array}{l}\text { Regresyon } \\
\text { katsayıları } \\
\text { Regression } \\
\text { coefficients }\end{array}$ & $\begin{array}{l}\text { Standart hata } \\
\text { Standard error }\end{array}$ & $\mathrm{R}^{2}$ & $\begin{array}{c}\text { Düzeltilmiş } \mathrm{R}^{2} \\
\text { Adjusted } \\
R^{2}\end{array}$ \\
\hline \multirow{3}{*}{50} & Sabite & 522.742 & 374.880 & \multirow{3}{*}{$0.70^{* *}$} & \multirow{3}{*}{0.64} \\
\hline & NDVI & 1135.238 & 443.627 & & \\
\hline & $\mathrm{CWSI}_{\mathrm{e}}$ & -1014.000 & 354.309 & & \\
\hline \multirow{3}{*}{62} & Sabite & 306.618 & 582.657 & \multirow{3}{*}{$0.87^{* * *}$} & \multirow{3}{*}{0.85} \\
\hline & NDVI & 976.308 & 465.080 & & \\
\hline & $\mathrm{CWSI}_{\mathrm{e}}$ & -813.526 & 480.254 & & \\
\hline \multirow{3}{*}{71} & Sabite & -360.406 & 421.595 & \multirow{3}{*}{$0.95 * * *$} & \multirow{3}{*}{0.94} \\
\hline & NDVI & 1728.224 & 315.899 & & \\
\hline & $\mathrm{CWSI}_{\mathrm{e}}$ & -526.722 & 279.977 & & \\
\hline \multirow{3}{*}{83} & Sabite & 321.541 & 1406.858 & \multirow{3}{*}{$0.76^{* *}$} & \multirow{3}{*}{0.71} \\
\hline & NDVI & 825.241 & 1154.765 & & \\
\hline & $\mathrm{CWSI}_{\mathrm{e}}$ & -696.462 & 788.493 & & \\
\hline \multirow{3}{*}{91} & Sabite & 1192.534 & 702.728 & \multirow{3}{*}{$0.88 * * *$} & \multirow{3}{*}{0.86} \\
\hline & NDVI & 140.166 & 489.049 & & \\
\hline & $\mathrm{CWSI}_{\mathrm{e}}$ & -1337.506 & 515.618 & & \\
\hline \multirow{3}{*}{113} & Sabite & 608.979 & 107.471 & \multirow{3}{*}{$0.98 * * *$} & \multirow{3}{*}{0.98} \\
\hline & NDVI & 332.767 & 102.145 & & \\
\hline & $\mathrm{CWSI}_{\mathrm{e}}$ & -688.252 & 52.653 & & \\
\hline
\end{tabular}

\footnotetext{
${ }^{\text {ns }}$ :Önemsiz, ${ }^{*}: p<0.05,{ }^{* *}: p<0.01, * * *: p<0.001, n=12$
}

Farklı bitkilerde yapılan çalışmalarda da stoma iletkenliği ile CWSI arasında önemli ilişkiler elde etmişlerdir. Ben-Gal ve ark. (2009) zeytinde yaptıkları çalışmada, termal görüntüler yardımıyla hesaplanan CWSI değerlerinin stoma iletkenliğini belirlemede kullanılabileceğini belirtmişlerdir. Zia ve ark. (2013) mısırda stoma iletkenliği ile CWSI arasındaki $R^{2}$ değerini 0.62 olarak elde etmişlerdir. 


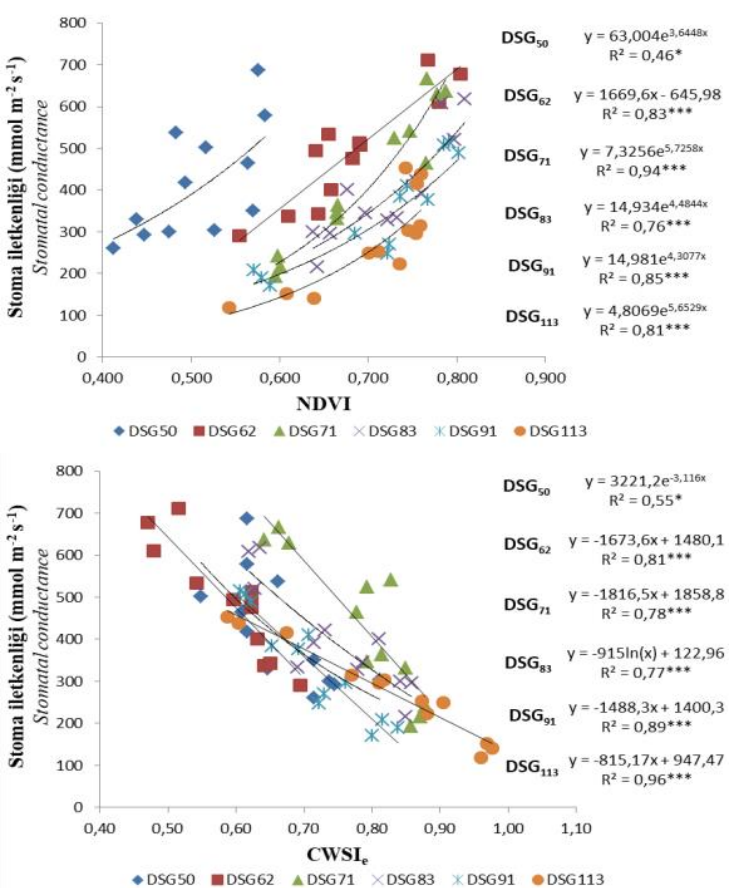

Şekil 4. Stoma iletkenliği ile indeksler arasındaki TDR analizi sonuçları

Figure 4. The results of TDR analysis between stomatal conductance and indices

\section{Klorofil okuması ile indeksler arasındaki ilişkiler}

Yetiştirme periyodu boyunca her ölçüm için klorofil okuması ile NDVI ve $\mathrm{CWSI}_{\mathrm{e}}$ değerleri arasındaki TDR analizleri Şekil 5'de, ÇDDR analizi sonuçları da Çizelge 5'de gösterilmiştir. Klorofil okuması ile NDVI arasındaki ilişki pozitif yönde olurken, $\mathrm{CWSI}_{\mathrm{e}}$ ile arsındaki ilişki ise negatif yönlü olmuştur. Elde edilen $\mathrm{R}^{2}$ değerleri NDVI için 0.39 $(p<0.05)$ ile $0.95(p<0.001)$ ve $\mathrm{CWSI}_{e}$ için 0.65 $(p<0.05)$ ile $0.92(p<0.001)$ arasında değişmiştir. En düşük değerler her iki indekste de $D_{S G_{50}}$ 'de gerçekleşmiştir. En yüksek $R^{2}$ değerleri ise NDVI için $\mathrm{DSG}_{71}$ ve $\mathrm{CWSI}_{\mathrm{e}}$ için $\mathrm{DSG}_{83}$ ' de elde edilmiştir.

Her iki indeksin de eşitlikte yer almasıyla $R^{2}$ değerlerinin özellikle $D_{S G_{50}}$ 'de oldukça yükseldiği görülmektedir (Çizelge 5). $\mathrm{R}^{2}$ değerleri 0.73 ile 0.95 arasında değişmiş olup tümü istatistiksel açıdan \%0.1 düzeyinde önemli bulunmuştur.

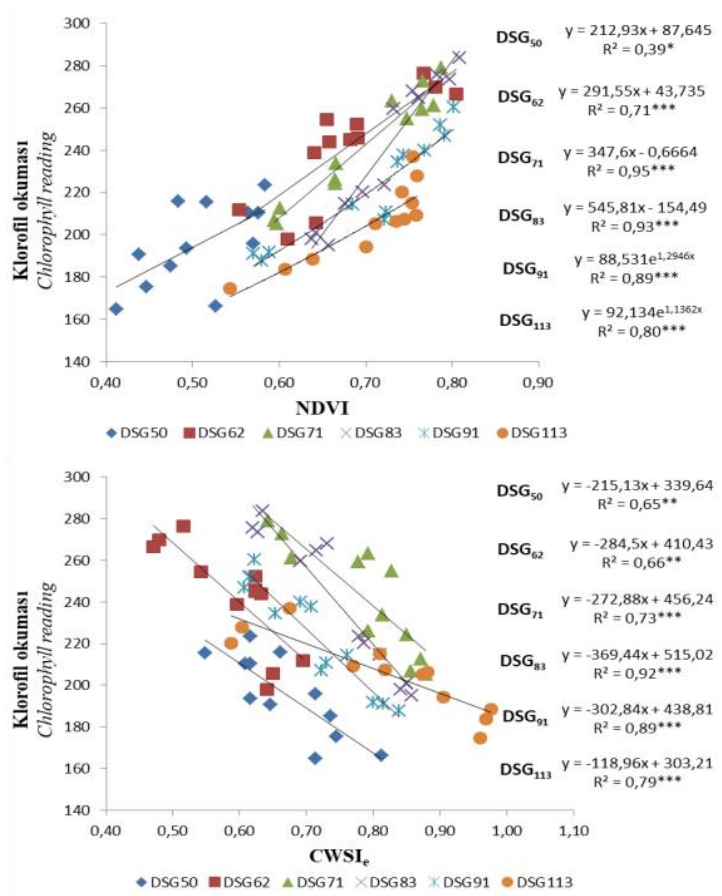

Şekil 5. Klorofil okuması ile indeksler arasındaki TDR analizi sonuçları

Figure 5. The results of TDR analysis between chlorophyll reading and indices

Çizelge 5. Klorofil okuması ile indeksler arasındaki ÇDDR analizi sonuçları Table 5. The results of ÇDDR analysis between chlorophyll reading and indices

\begin{tabular}{|c|c|c|c|c|c|}
\hline DSG & $\begin{array}{l}\text { Model } \\
\text { Model }\end{array}$ & $\begin{array}{l}\text { Regresyon } \\
\text { katsayıları } \\
\text { Regression } \\
\text { coefficients }\end{array}$ & $\begin{array}{l}\text { Standart hata } \\
\text { Standard error }\end{array}$ & $\mathrm{R}^{2}$ & $\begin{array}{c}\text { Düzeltilmiş } \mathrm{R}^{2} \\
\text { Adjusted } \\
R^{2}\end{array}$ \\
\hline & Sabite & 248.014 & 45.204 & & \\
\hline \multirow[t]{2}{*}{50} & NDVI & 142.311 & 53.494 & $0.80 * * *$ & 0.76 \\
\hline & $\mathrm{CWSI}_{\mathrm{e}}$ & -185.801 & 42.724 & & \\
\hline & Sabite & 174.857 & 159.704 & & \\
\hline \multirow[t]{2}{*}{62} & NDVI & 196.461 & 127.477 & $0.73 * *$ & 0.67 \\
\hline & $\mathrm{CWSI}_{\mathrm{e}}$ & -112.310 & 131.636 & & \\
\hline \multirow{3}{*}{71} & Sabite & 65.786 & 62.142 & & \\
\hline & NDVI & 304.974 & 46.563 & $0.95 * * *$ & 0.94 \\
\hline & $\mathrm{CWSI}_{\mathrm{e}}$ & -46.815 & 41.268 & & \\
\hline \multirow{3}{*}{83} & Sabite & 152.598 & 169.667 & & \\
\hline & NDVI & 302.864 & 139.264 & $0.95 * * *$ & 0.94 \\
\hline & $\mathrm{CWSI}_{\mathrm{e}}$ & -176.313 & 95.092 & & \\
\hline \multirow{3}{*}{91} & Sabite & 265.215 & 126.364 & & \\
\hline & NDVI & 121.857 & 87.940 & $0.91 * * *$ & 0.89 \\
\hline & $\mathrm{CWSI}_{\mathrm{e}}$ & -180.496 & 92.718 & & \\
\hline \multirow{3}{*}{113} & Sabite & 180.584 & 41.531 & & \\
\hline & NDVI & 120.838 & 39.472 & $0.90 * * *$ & 0.88 \\
\hline & $\mathrm{CWSI}_{\mathrm{e}}$ & -73.292 & 20.347 & & \\
\hline
\end{tabular}

\footnotetext{
${ }^{\text {ns }}:$ Önemsiz, ${ }^{*}: p<0.05,{ }^{* *}: p<0.01,{ }^{* * *}: p<0.001, n=12$
} 
Farklı bitkilerde yapılan çalışmalarda da söz konusu indeksler ile klorofil arasında önemli ilişkiler olduğu belirtilmiştir (Penuelas ve Inoue, 1999; Köksal ve ark., 2010; Camoglu ve ark., 2013; Camoglu ve ark., 2018).

Yaprak su potansiyeli ile indeksler arasındaki ilişkiler

Yaprak su potansiyeli ile NDVI ve $\mathrm{CWSI}_{\mathrm{e}}$ değerleri arasındaki TDR analizleri gösteren Şekil 6 incelendiğinde; YSP ile NDVI arasındaki $R^{2}$ değerleri, ölçüm günlerine bağlı olarak 0.13 ( $p>0.05$, önemsiz) ile $0.91(p<0.001), C^{2}{ }^{2} I_{e}$ ile $0.53 \quad(p<0.05)$ ile $0.91 \quad(p<0.001)$ arasında değişmiştir. Elde edilen $R^{2}$ değerleri ilk ölçüm gününden sonra artmıştır. NDVI ve $\mathrm{CWSI}_{\mathrm{e}}$ için en yüksek değerler sırasıyla $D_{S G_{71}}$ ve $D_{S G_{113}}$ 'de elde edilmiştir. Mastrorilli ve ark. (2010) domateste farklı su stresine bağlı olarak ölçtükleri YSP ve NDVI arasındaki $R^{2}$ değerini 0.95 olarak belirlemişlerdir. Söz konusu çalışmada da aralarındaki ilişkinin oldukça önemli olduğu ve YSP'nin NDVI ile tahmin edilebileceği ortaya çıkmıştır. Farklı bitkilerde yapılan çalışmalarda da NDVI ve CWSI değerleri ile YSP arasında benzer bulgular elde edilmiştir (Penuelas and Inoue, 2000; Cohen ve ark., 2005; Möller ve ark., 2007; Ben-Gal ve ark., 2009; O'Shaughnessy ve ark., 2011; Camoglu ve Genc, 2013).
ÇDDR analizi sonuçlarını gösteren Çizelge 6 incelendiğinde, yine her iki indeksin de eşitlikte yer almasıyla $\mathrm{R}^{2}$ değerlerinde artış gözlenmiştir. Söz konusu değerler ölçüm günlerine göre 0.56 ile 0.93 arasında değişmiştir. Sadece ilk ölçümde elde edilen $\mathrm{R}^{2}$ değeri \%5 düzeyinde önemli bulunurken diğerleri \%0.1 düzeyinde önemli çıkmıştır.
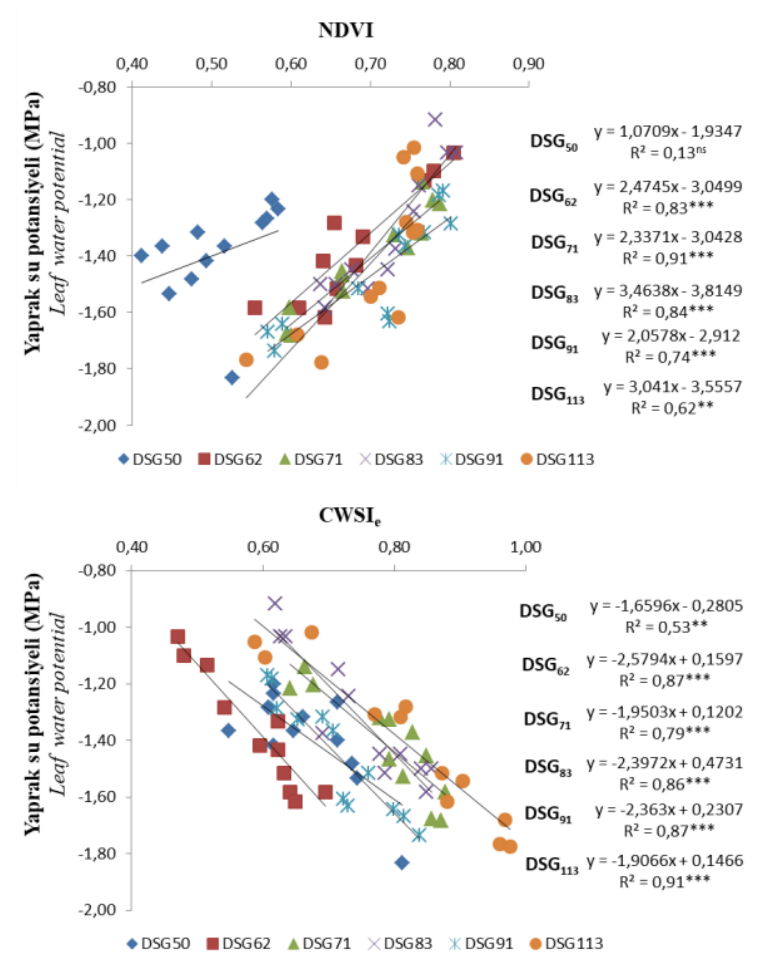

Şekil 6. Yaprak su potansiyeli ile indeksler arasındaki TDR analizi sonuçları

Figure 6. The results of TDR analysis between leaf water potential and indices

Çizelge 6. Yaprak su potansiyeli ile indeksler arasındaki ÇDDR analizi sonuçları

Table 6. The results of ÇDDR analysis between stomatal conductance and indices

\begin{tabular}{|c|c|c|c|c|c|}
\hline DSG & $\begin{array}{l}\text { Model } \\
\text { Model }\end{array}$ & $\begin{array}{l}\text { Regresyon } \\
\text { katsayıları } \\
\text { Regression } \\
\text { coefficients }\end{array}$ & $\begin{array}{l}\text { Standart hata } \\
\text { Standard error }\end{array}$ & $\mathrm{R}^{2}$ & $\begin{array}{c}\text { Düzeltilmiş } \mathrm{R}^{2} \\
\text { Adjusted } \\
R^{2}\end{array}$ \\
\hline & Sabite & -0.572 & 0.573 & & \\
\hline \multirow[t]{2}{*}{50} & NDVI & 0.471 & 0.679 & $0.56^{*}$ & 0.46 \\
\hline & $\mathrm{CWSI}_{\mathrm{e}}$ & -1.580 & 0.542 & & \\
\hline \multirow{3}{*}{62} & Sabite & -1.002 & 0.753 & & \\
\hline & NDVI & 0.987 & 0.601 & $0.91 * * *$ & 0.88 \\
\hline & $\mathrm{CWSI}_{\mathrm{e}}$ & -1.751 & 0.621 & & \\
\hline \multirow{3}{*}{71} & Sabite & -2.145 & 0.510 & & \\
\hline & NDVI & 1.755 & 0.382 & $0.93 * * *$ & 0.92 \\
\hline & $\mathrm{CWSI}_{\mathrm{e}}$ & -0.626 & 0.339 & & \\
\hline \multirow{3}{*}{83} & Sabite & -0.993 & 1.870 & & \\
\hline & NDVI & 1.221 & 1.535 & $0.87 * * *$ & 0.84 \\
\hline & $\mathrm{CWSI}_{\mathrm{e}}$ & -1.611 & 1.048 & & \\
\hline \multirow{3}{*}{91} & Sabite & 0.644 & 1.195 & & \\
\hline & NDVI & -0.301 & 0.832 & $0.87^{* * *}$ & 0.84 \\
\hline & $\mathrm{CWSI}_{\mathrm{e}}$ & -2.647 & 0.877 & & \\
\hline \multirow{3}{*}{113} & Sabite & -0.657 & 0.530 & & \\
\hline & NDVI & 0.784 & 0.503 & $0.93 * * *$ & 0.91 \\
\hline & $\mathrm{CWSI}_{\mathrm{e}}$ & -1.601 & 0.259 & & \\
\hline
\end{tabular}

\footnotetext{
${ }^{\text {ns }}:$ Önemsiz, ${ }^{*}: p<0.05,{ }^{* *}: p<0.01,{ }^{* * *}: p<0.001, n=12$
} 
Yaprak oransal su içeriği ile indeksler arasındaki ilişkiler

Yaprak oransal su içeriği ile indeksler arasında yapılan TDR analizi sonucu elde edilen $\mathrm{R}^{2}$ değerleri her iki indeks için de ilk ölçüm gününde önemsiz bulunmuştur (Şekil 7). Diğer ölçüm günlerinde söz konusu değerler artmış DSG $_{62}$ 'de 0.68 'e yükselerek \%1 düzeyinde önemli bulunmuştur. Sonraki ölçümlerde ise önemlilik düzeyi \%0.1 seviyesine yükselmiştir. En yüksek $\mathrm{R}^{2}$ değerleri her iki indekste de $D_{S G_{91}}$ 'de elde edilmiştir.

ÇDDR analiz sonuçlarına göre iki indeksin de eşitlikte yer alması durumunda $\mathrm{R}^{2}$ değerlerinin nispeten yükseldiği görülmektedir (Çizelge 7). Söz konusu değerler TDR analizinde olduğu gibi burada da $\mathrm{DSG}_{50}$ 'de önemsiz bulunmuştur. En yüksek değer son ölçümde $\left(D_{S G_{113}}\right)$ elde edilmiştir. $R^{2}$ değerlerindeki en fazla artış da yine söz konusu ölçüm gününde olmuştur. Camoglu ve ark. (2018) biberde TDR analizi sonucu NDVI ve CWSI $I_{e}$ için sırasıyla 0.65 ve 0.26 olan $\mathrm{R}^{2}$ değerinin, her iki indeksin beraber kullanılmasıyla 0.78'e yükseldiğini bildirmişlerdir. Bitkilerin su içeriği ile indeksler arasındaki ilişkilerin önemli olduğu
Jones ve ark. (2004) ile Camoglu ve ark. (2013) tarafından da bildirilmiştir.

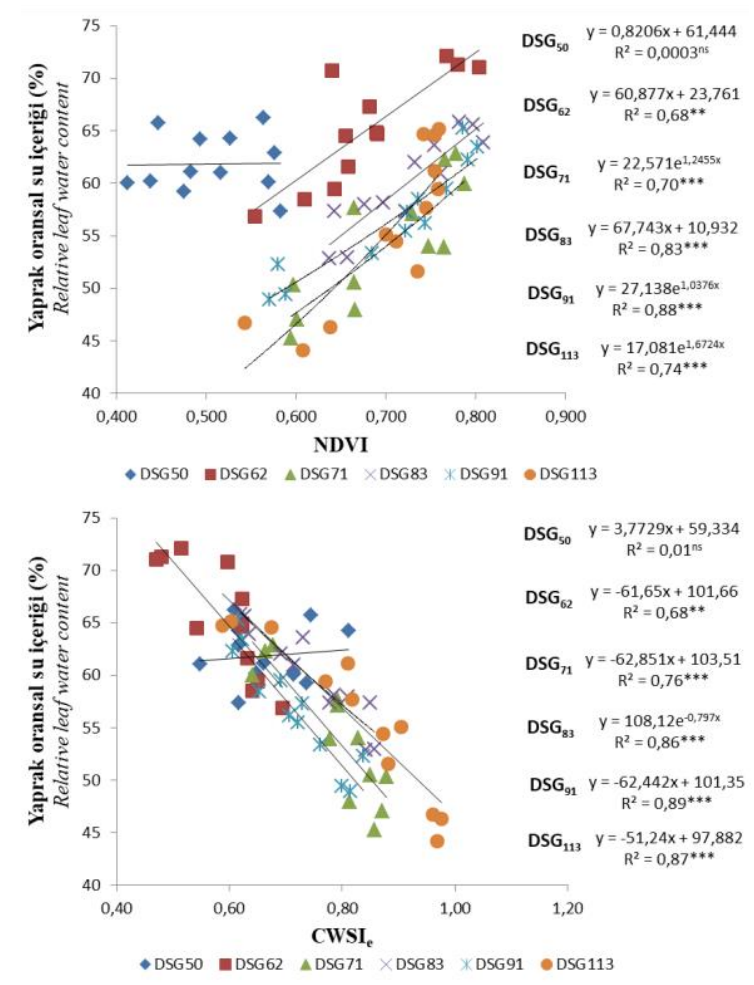

Şekil 7. Yaprak oransal su içeriği ile indeksler arasındaki TDR analizi sonuçları

Figure 7. The results of TDR analysis between relative leaf water content and indices

Çizelge 7. Yaprak oransal su içeriği ile indeksler arasındaki ÇDDR analizi sonuçları

Table 7. The results of ÇDDR analysis between relative leaf water content and indices

\begin{tabular}{|c|c|c|c|c|c|}
\hline DSG & $\begin{array}{l}\text { Model } \\
\text { Model }\end{array}$ & $\begin{array}{l}\text { Regresyon } \\
\text { katsayıları } \\
\text { Regression } \\
\text { coefficients }\end{array}$ & $\begin{array}{l}\text { Standart hata } \\
\text { Standard error }\end{array}$ & $\mathrm{R}^{2}$ & $\begin{array}{c}\text { Düzeltilmiş } \mathrm{R}^{2} \\
\text { Adjusted } \\
R^{2}\end{array}$ \\
\hline & Sabite & 58.157 & 14.319 & & \\
\hline \multirow[t]{3}{*}{50} & NDVI & 1.602 & 16.945 & $0.01^{\mathrm{ns}}$ & -0.21 \\
\hline & $\mathrm{CWSI}_{\mathrm{e}}$ & 4.150 & 13.534 & & \\
\hline & Sabite & 62.069 & 36.011 & & \\
\hline \multirow[t]{3}{*}{62} & NDVI & 32.670 & 28.744 & $0.70 * *$ & 0.64 \\
\hline & $\mathrm{CWSI}_{\mathrm{e}}$ & -32.327 & 29.682 & & \\
\hline & Sabite & 66.019 & 29.703 & & \\
\hline \multirow[t]{3}{*}{71} & NDVI & 29.148 & 22.256 & $0.79 * * *$ & 0.75 \\
\hline & $\mathrm{CWSI}_{\mathrm{e}}$ & -40.994 & 19.725 & & \\
\hline & Sabite & 79.896 & 35.958 & & \\
\hline \multirow[t]{3}{*}{83} & NDVI & 13.740 & 29.515 & $0.88 * * *$ & 0.86 \\
\hline & $\mathrm{CWSI}_{\mathrm{e}}$ & -40.097 & 20.153 & & \\
\hline & Sabite & 69.857 & 27.442 & & \\
\hline \multirow[t]{3}{*}{91} & NDVI & 21.621 & 19.098 & $0.90 * * *$ & 0.88 \\
\hline & $\mathrm{CWSI}_{\mathrm{e}}$ & -40.240 & 20.135 & & \\
\hline & Sabite & 62.256 & 14.066 & & \\
\hline \multirow[t]{2}{*}{113} & NDVI & 35.608 & 13.369 & $0.93 * * *$ & 0.92 \\
\hline & $\mathrm{CWSI}_{\mathrm{e}}$ & -38.376 & 6.891 & & \\
\hline
\end{tabular}

\footnotetext{
${ }^{\text {ns }}:$ Önemsiz, ${ }^{*}: p<0.05,{ }^{* *}: p<0.01,{ }^{* * *}: p<0.001, n=12$
} 


\section{Sonuçlar}

$\mathrm{Bu}$ çalışmada domates bitkisinin fizyolojik özelliklerinden stoma iletkenliği, yaprak su potansiyeli, yaprak oransal su içeriği ve klorofil değeri ile uzaktan algılama indekslerinden NDVI ve CWSI arasındaki ilişkiler tek değişkenli ve çok değişkenliği doğrusal regresyon analizlerini kullanarak değerlendirilmiştir. Yapılan analizler sonucunda domatesin fizyolojik özellikleri ile uzaktan algılama indeksleri arasında istatistiksel olarak önemli $\mathrm{R}^{2}$ değerleri elde edilmiştir. Illk ölçümden itibaren söz konusu değerler artış göstermiştir. Bu nedenle fizyolojik özelliklerin daha doğru tahmini için bu konu dikkate alınmalıdır. Hem CWSI hem de NDVI değerlerinin yer aldığı çok değişkenli regresyon modellerinde $\mathrm{R}^{2}$ değerleri tek değişkenli regresyona göre daha da yükselmiştir. Söz konusu koşulda en yüksek $R^{2}$ değerleri; stoma iletkenliği için 0.98, klorofil için 0.95 , yaprak su potansiyeli için 0.93 ve yaprak oransal su içeriği için 0.93 olarak bulunmuştur. Bu durumda, söz konusu fizyolojik özelliklerin doğru tahmini için her iki indeksin de kullanılması önerilebilir. Ayrıca, dikimden sonraki günün de dikkate alınarak, o gün için elde edilen modelin kullanılması, söz konusu fizyolojik özelliğin daha doğru tahmin edilmesini sağlayacaktır.

Sonuç olarak, domates bitkisinin su stresine karşı oldukça duyarlı olduğu, su stresinin fizyolojik özellikler ve uzaktan algılama indeksleri ile belirlenebileceği söylenebilir. Bununla birlikte, su stresinin belirlenmesinde kullanılan önemli fizyolojik özelliklerin bitkiye zarar vermeden, hızlı, anlık ve doğru tahmininde termografi tekniğinin ve doğrudan NDVI değerini veren sensörlerin kullanışlı olabileceği sonucuna varılmıştır.

\section{Ekler}

$\mathrm{Bu}$ çalışma Çanakkale Onsekiz Mart Üniversitesi Bilimsel Araştırma Projeleri FHD2017-1190 no'lu proje kapsamında desteklenmiştir.

\section{Kaynaklar}

Ackley, W.B. (1954). Water contents and water deficits of leaves of bartlett pear trees on the two rootstocks $P$. communis and $P$. serotina. Proceedings of the American Society for Horticultural Science, 64, 181185.

Akçan, M., Çamoğlu, G., \& Demirel, K. (2016). Termografi tekniğini kullanarak çimin su stresinin belirlenmesi. 13. Ulusal Kültürteknik Kongresi (346-354), Antalya.

Anonim (2018). Iklim Verileri. Meteoroloji Genel Müdürlüğü, Ankara.Ben-Gal, A., Agam, N., Alchanatis, V., Cohen, Y., Yermiyahu, U., Zipori, I., et al. (2009). Evaluating water stress in irrigated olives: correlation of soil water status, tree water status, and thermal imagery. Irrigation Science, 27, 367-376.

Camoglu, G., \& Genc, L. (2013). Determination of water stress using thermal and spectral indices from green bean canopy. Fresenius Environmental Bulletin, 22(10a), 3078-3088.

Camoglu, G., Kaya U., Akkuzu, E., Genc, L., Gurbuz, M., Pamuk Mengu, G., et al. (2013). Prediction of leaf water status using spectral indices at young olive trees. Fresenius Environmental Bulletin, 22(9a), 27132720.

Camoglu, G., Demirel, K., \& Genc, L. (2018). Use of infrared thermography and hyperspectral data to detect effects of water stress on pepper. Quantitative InfraRed Thermography Journal, 15(1), 81-94.

Cohen, Y., Alchanatis, V., Meron, M., Saranga S., \& Tsipris, J. (2005). Estimation of leaf water potential by thermal imagery and spatial analysis. Journal of Experimental Botany, 56, 1843-1852.

Covey, R. (1999). Remote sensing in precision agriculture: an educational primer, lowa State University, Ames Remote, http://www.amesremote.com/papers.htm (Erişim tarihi: 14 Temmuz 2018).

Datt, B. (1998). Remote sensing of chlorophyll $a$, chlorophyll $b$, chlorophyll $a+b$, and total carotenoid content in eucalyptus leaves. Remote Sensing of Environment, 66, 111-121.

Demirel, K., Camoglu, G., Genc, L., \& Kizil, U. (2014). The variation of plant stress indicators and some traits under different irrigation and nitrogen levels in the rocket. Fresenius Environmental Bulletin, 23(5), 1238-1248.

Jacquemoud, S., \& Ustin, S.I. (2001). Leaf optical properties: A state of the Art. Proc. 8th Int. Symp. Phyisical Measurements and Signatures in Remote Sensings (223-323 pp), France.

Jones, H.G. (1999). Use of infrared thermometry for estimation of stomatal conductance as a possible aid to irrigation scheduling. Agricultural and Forest Meteorology, 95, 139-149.

Jones, H.G., Stoll, M., Santos, T., de Sousa, C., Chaves, M.M. et al.(2002). Use of infrared thermography for monitoring stomatal closure in the field: application to grapevine. Journal of Experimental Botany, 53, 2249-2260.

Jones, C.L., Weckler, P.R., Maness, N.O., Stone, M.L., \& Jayasekara, R. (2004). Estimating water stress in plants using hyperspectral sensing, ASAE/CSAE 
Annual International Meeting, 1-4 August, Paper Number: 043065.

Köksal, E.S., Üstün, H., Özcan, H., \& Güntürk, A. (2010). Estimating water stressed dwarf green bean pigment concentration through hyperspectral indices. Pakistan Journal of Botany, 42(3), 1895-1901.

Mastrorilli, M., Campi, P., Palumbo, A.D., \& Modugno, F. (2010). Ground-based remote sensing for assessing tomato water-status. Italian Journal of Agronomy, 5, 177-183.

Monteith, J.L., \& Unsworth, M.L. (1990). Principles of environmental physics. 2nd ed. Edward Arnold, London, United Kingdom, 414p.

Morales, I., \& Urrestarazu, M. (2013). Thermography study of moderate electrical conductivity and nutrient solution distribution system effects on grafted tomato soilless culture. Hortscience, 48(12), 15081512.

Möller, M., Alchanatis, V., Cohen, Y., Meron, M., Tsipris, J., et al. (2007). Use of thermal and visible imagery for estimating crop water status of irrigated grapevine. Journal of Experimental Botany, 58, 827-838.

Nardella, E., Giuliani, M.M., Gatta, G., Tarantino, E., \& De Caro, A. (2008). Irrigation scheduling in processing tomato crop cultivated in southern Italy: the role of physiological parameters. Italian Journal of Agronomy, 3(3), 685-686.

Nicacias, M.M. (2009). Evaluating the effect of moisture stress on tomato using non-destructive remote sensing techniques. Master Thesis, School of
Agricultural and Environmental Science, Faculty of Science and Agriculture, University of Limpopo.

O’Shaughnessy, S.A., Evett, S.R., Colaizzi, P.D., \& Howell, T.A. (2011). Using radiation thermography and thermometry to evaluate crop water stress in soybean and cotton. Agricultural Water Management, 98, 1523-1535.

Penuelas, J., \& Inoue, Y. (1999). Reflectance indices indicative of changes in water and pigment content of peanut and wheat leaves. Photosynthetica, 36(3), 335-360.

Penuelas, J., \& Inoue, Y. (2000). Reflectance assessment of canopy $\mathrm{CO}_{2}$ uptake. International Journal of Remote Sensing, 21, 3353-3356.

Rouse, J.W., Hass, R.H., Schell, J.A., \& Deering, D.W. (1973). Monitoring vegetation systems in the great plains with ERTS. In: Proceedings of the Third ERTS Symposium (309-317 pp), (Goddard Space Flight Center), DC: NASA, NASA SP-351, Washington.

Smart, R.E., \& Bingham, G.E. (1974). Rapid estimates of relative water content. Plant Physiology, 53, 258260.

Sönmez, N.K., Aslan, G.E., \& Kurunç, A. (2015). Farklı tuz stresi altındaki domates bitkisinin spektral yansıma ilişkileri. Tarım Bilimleri Dergisi, 21, 585-595.

Zia, S., Romano, G., Spreer, W., Sanchez, C., Cairns, J., et.al. (2013). Infrared thermal imaging as a rapid tool for identifying water-stress tolerant maize genotypes of different phenology. Journal of Agronomy and Crop Science, 199, 75-84. 